\title{
Ações de vigilância para influenza aviária desenvolvida no Brasil, no período de 2004 e 2007
}

[Avian influenza surveillance activities, developed in Brazil from 2004 to 2007]

\author{
M.A. Mota ${ }^{1}$, F.S. Lima ${ }^{1}$, P.F.N. Oliveira ${ }^{1}$, M.P. Guimarães ${ }^{2}$
}

${ }^{1}$ Ministério da Agricultura, Pecuária e Abastecimento - Esplanada dos Ministérios - Brasília, DF
${ }^{2}$ Instituto de Ciências Biológicas - Universidade Federal de Minas Gerais - Belo Horizonte, MG

\section{RESUMO}

No início dos anos 2000, o Brasil se consolidou como maior exportador mundial de carne de frango, mesmo período em que se observou a emergência global de focos de HPAI. Para assegurar a qualidade sanitária do produto avícola nacional, o Mapa organizou um programa oficial de vigilância para o vírus de IA. Na primeira fase, foram coletados 106.226 soros e 7.017 pools de suabes traqueais e cloacais, provenientes de granjas avícolas de produção comercial intensiva de frangos de corte, no período entre janeiro de 2004 e março de 2005. Não se obteve isolamento viral para IA, porém foi identificado um conglomerado epidemiológico de 24 municípios, delineado pela interpolação de dados relacionados às localizações geográficas, e os resultados sorológicos das amostras dessas origens, ELISA reagente para IA, no estado de Rondônia. Na segunda fase da vigilância, três distintas ações para pesquisa do vírus de IA foram executadas entre 2006 e 2007, em: 1) aves comerciais de corte de criação intensiva; 2) aves de reprodução; e 3) aves migratórias e de subsistência. Não houve identificação de resposta sorológica ou isolamento de vírus de IA em aves dos grupos 1 e 2 . Foram isolados vírus de IA do subtipo H3 em aves migratórias, capturadas nos estados de Pará e Pernambuco. Também foram identificados vírus de IA dos subtipos H2, H3 e H4 em aves de subsistência, de propriedades localizadas no Amazonas, Pará, Pernambuco, Rio Grande do Sul e Santa Catarina. Observou-se risco sanitário para LPAI associado às populações de aves silvestres e de subsistência localizadas em áreas próximas ao sistema comercial. Estudos adicionais serão necessários para se avaliar o risco associado à introdução de IA no sistema comercial avícola brasileiro.

Palavras-chave: avicultura, influenza aviária, estratégias de controle, Brasil

\begin{abstract}
In the early 2000s Brazil had established itself as the world's largest exporter of poultry meat, the same period in which the emergence of HPAI global outbreaks was observed. To ensure the national health quality of Brazilian poultry product, MAPA organized an official AI surveillance program. In the first stage, during the period between January 2004 and March 2005, 106.226 sera were collected and 7.017 tracheal and cloacae pools of swabs were obtained from intensive commercial broiler farms. No AI virus isolation was obtained, however, an epidemiological cluster was identified in the state of Rondonia, outlined by the interpolation of data related to municipalities' geographic location and serological response to AI in ELISA tests. Between 2006 and 2007, during the second stage, three AI surveillance actions were executed in: 1) intensive commercial broiler farms, 2) breeding farms and 3) migratory and backyard birds. There was neither serological response identification nor IA virus isolation in birds belonging to groups 1 and 2. H3 LPAI subtype viruses were isolated from migratory birds captured in the states of Pará and Pernambuco. H2, H3 and H4 LPAI subtypes were also identified in backyard birds from samples collected in the states of Amazonas, Pará, Pernambuco, Rio Grande do Sul and Santa Catarina. There are health risks to LPAI associated to wild and backyard bird populations located in areas close to commercial farms. Additional studies are needed for risk assessment regarding the possibility of AI introduction in the Brazilian commercial poultry system.
\end{abstract}

Keywords: poultry, avian influenza, control strategies, Brazil

Recebido em 15 de maio de 2012

Aceito em 15 de março de 2013

E-mail: marcelo.mota@agricultura.gov.br 


\section{INTRODUÇÃO}

Os vírus de influenza aviária (IA) são reconhecidos como causa de significantes números de infecções e doenças, causadas usualmente no trato respiratório superior de mamíferos silvestres e marinhos, humanos, equinos, suínos, além de várias espécies de aves (Alexander, 1995; Lvov et al., 1978; Webster et al., 1992). Já houve registro de casos de ocorrência de focos de IA em estabelecimentos avícolas comerciais e em aglomerados de aves de subsistência e silvestres em todos os continentes do mundo (FAO, 2007). Os grandes prejuízos econômicos causados pela doença referem-se à ocorrência de cepas de influenza aviária de alta patogenicidade (HPAI), em criações de aves domésticas de produção intensiva, com associações epidemiológicas a mercados de vendas de aves vivas.

Como forma de subsidiar a certificação sanitária e a manutenção e abertura de novos mercados, o Ministério da Agricultura, Pecuária e Abastecimento do Brasil (Mapa) realizou um estudo inédito de monitoramento, visando identificar a presença de circulação de vírus de IA no sistema de produção comercial avícola nacional. O objetivo deste trabalho foi avaliar os padrões de circulação de IA nas populações avícolas susceptíveis à doença.

\section{MATERIAL E MÉTODOS}

Para a primeira fase do estudo, foi realizada investigação em 7.017 granjas avícolas de produção comercial intensiva de frangos de corte, distribuídas em 1.067 municípios, de 14 estados brasileiros (Fig. 1). Todas as propriedades de origem das aves estavam cadastradas pelo serviço veterinário oficial e cumpriam os requisitos mínimos de biossegurança estabelecidos em legislação nacional (Brasil, 1998).

As amostras foram coletadas entre janeiro de 2004 e março de 2005. Equipes de médicos veterinários do sistema oficial de inspeção federal realizaram a coleta de amostras em aves com mais de 21 dias de idade. Para composição de cada lote de amostras, foram efetuadas coletas de soro sanguíneo de, pelo menos, 15 aves, pools de 15 suabes traqueais e 15 suabes cloacais, sendo que cada suabe continha amostras de duas aves.

Entre janeiro de 2006 e novembro de 2007, as ocorrências de sinais clínicos nervosos e digestivos, seguidos de síndrome respiratória, associados à mortalidade acumulada superior a $10 \%$ nos lotes de produção comercial intensiva de frangos de corte, foram comunicadas ao serviço veterinário oficial, em todo o território nacional. As comunicações foram seguidas por investigação e coleta de amostras biológicas para a realização de pesquisa sorológica e tentativa de isolamento viral.

Para composição de cada lote de amostras, em cada propriedade sob investigação, foram efetuadas coletas de soro sanguíneo de, pelo menos, 15 aves, pools de 15 suabes de traqueia e de 15 suabes de cloaca, sendo que cada suabe continha amostras de duas aves.

Durante o mesmo período, o serviço veterinário oficial brasileiro realizou coleta de 30 soros sanguíneos, para cada lote de reprodução com mais de 20 semanas de idade, nos estabelecimentos avícolas registrados no Mapa e habilitados à exportação de material genético.

Populações de aves silvestres, em sítios de invernada localizados nos estados brasileiros do Amapá, Bahia, Maranhão, Mato Grosso do Sul, Pará, Pernambuco, Rio Grande do Norte e Rio Grande do Sul, foram amostradas. As atividades foram conduzidas por equipe composta por representantes do Mapa, Universidade Federal Rural de Pernambuco, Universidade de São Paulo e do Instituto Brasileiro de Recursos Naturais e Renováveis. Foram realizados captura das aves migratórias, medição biométrica, coleta de material biológico, anilhamento e posterior liberação das aves (Brasil, 2002). As capturas foram concentradas entre os meses de setembro de 2006 e abril de 2007, período que coincidiu com a estação de migração de aves das ordens Anseriforme e Charadriiforme, desde o Hemisfério Norte, para a América do Sul.

Paralelo a esta atividade, os criatórios de subsistência, localizados no raio de $10 \mathrm{~km}$ ao redor dos sítios de invernada, foram identificados. Foram realizadas coletas individuais de suabe traqueal e cloacal de todas 
as aves mantidas em sistema de criação não comercial ou intensivo nessas áreas.

Todas as amostras, destinadas a exames sorológicos e virológicos, foram mantidas resfriadas desde o momento da coleta até seu recebimento pelo Laboratório e posteriormente mantidas a $-70^{\circ} \mathrm{C}$. Todas as provas laboratoriais foram realizadas no Lanagro-SP, referência oficial para doenças avícolas no Brasil.

Utilizou-se o kit Flockcheck $^{\odot}\left(\right.$ IDEXX $\left.^{\odot}\right)$ para a realização dos testes ELISA. As amostras reagentes foram submetidas à confirmação de resultado em IDGA. Os antígenos foram fornecidos pelo Centro de Referência de Doenças Avícolas do Serviço de Inspeção Agrícola do Animal and Plant Health Inspection Services do United States Department of Agriculture. Todos os kits diagnósticos utilizados estavam registrados no Brasil (OIE, 2004).

Para o teste virológico, os pools de suabes de traqueia e cloaca, suspensos em solução antibacteriana, foram centrifugados a $2.000 \mathrm{~g}$ por 10 minutos, e os sobrenadantes armazenados até o momento de uso. Os sobrenadantes foram inoculados na cavidade alantoide de ovos embrionados de galinhas $S P F$, com oito a 10 dias de incubação, por período de uma semana. Para ser considerado positivo no teste de isolamento de vírus hemaglutinante, o líquido alantoide recuperado dos ovos embrionados deveriam apresentar resultado positivo em prova de hemaglutinação. Em caso de teste negativo, o procedimento foi repetido três vezes, antes de a amostra ser considerada negativa e descartada. Para caracterização da variante de hemaglutinina, presente na resposta sorológica das amostras isoladas, procedeu-se à realização de teste de inibição de hemaglutinação (Brasil, 1994).

Os mapas apresentados neste trabalho provêm de cartas geográficas do Brasil em escala 1:500.000 e foram produzidos pelo Instituto Brasileiro de Geografia e Estatística. As análises de conglomerados epidemiológicos foram realizadas, com alogarítimos computacionais gráficos, com significância estatística associada via simulação de Monte Carlo, utilizando-se software SaTScan v.8.2.1 (Kulldorff e Nagarwalla, 1995; Kulldorf, 2009).
A avaliação do tamanho da amostragem realizada em cada propriedade e por município participante do trabalho foi realizada com o uso do software FreeCalc v2. (Cameron e Baldock, 1998).

\section{RESULTADOS}

Para realizar a avaliação de circulação do vírus de IA em plantéis avícolas brasileiros, o estudo abrangeu lotes de produção comercial intensiva de frangos de corte em 1.067 municípios, dos estados da Bahia, Espírito Santo, Goiás, Mato Grosso, Mato Grosso do Sul, Minas Gerais, Paraná, Rio Grande do Sul, Rondônia, São Paulo, Santa Catarina, Sergipe e Tocantins, além do Distrito Federal, totalizando 7.017 lotes de amostras (Fig. 1).

Foram coletados 106.126 soros de aves. Todos os lotes de amostras foram submetidos ao teste de ELISA. Foi observada positividade em 5.230 amostras de soro, oriundas de 1.937 lotes. Todas as amostras positivas ao teste de ELISA foram submetidas em sequência à prova de IDGA. Não ocorreu confirmação de positividade em nenhum lote.

Foram realizadas tentativas de isolamento viral em 3.694 pools de suabes traqueais e de suabes cloacais. Todos os lotes de amostras com algum resultado sorológico positivo tiveram pools de suabes submetidos ao isolamento viral (Tab. 1.). Os resultados obtidos nos testes de ELISA das amostras provenientes do estado de Rondônia possibilitaram a delimitação de um conglomerado epidemiológico, via simulação de Monte Carlo, formado pelo conjunto de 24 municípios, onde a reatividade das amostras ao ELISA foi superior ao esperado, levando-se em consideração os resultados obtidos nas demais granjas do país $(\mathrm{P}=0,005)$ (Fig. 2).

Em pelo menos um município dos estados de Mato Grosso, Paraná, Rondônia, São Paulo, Santa Catarina e Sergipe, não foi possível confirmar resultados negativos nas amostras de soro provenientes de lotes de produção comercial, após a realização da prova de IDGA $(\mathrm{P}>0,05)$ (Tab. 2). 


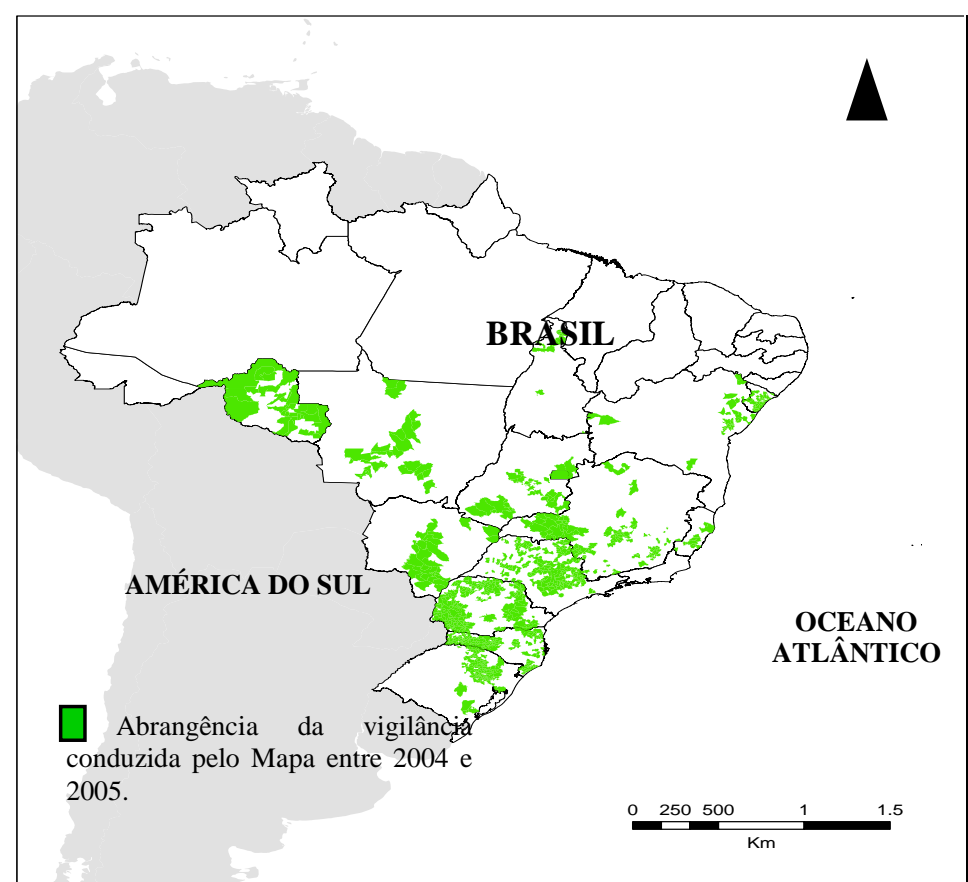

Figura 1. Área de abrangência do Programa Oficial de Vigilância ao Vírus de IA, no sistema de produção comercial avícola intensivo brasileiro, conduzido pelo Mapa, entre 2004 e 2005.

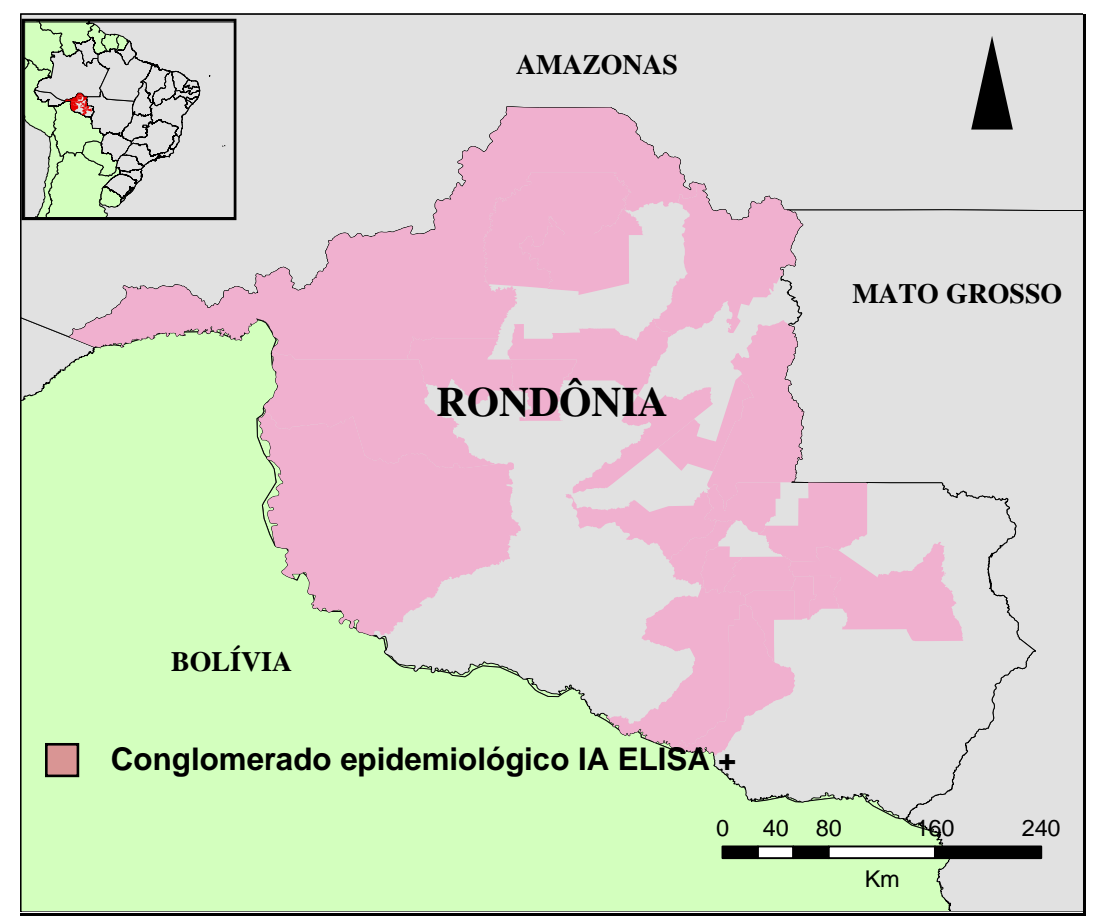

Figura 2. Conglomerado formado em 24 municípios do estado de Rondônia, relacionado à ocorrência de soropositividade no teste de ELISA para IA, acima da média observada no restante da área do país. Amostras obtidas pelo Programa Oficial de Vigilância ao Vírus de IA, no sistema de produção comercial avícola intensivo brasileiro, conduzido pelo Mapa, entre 2004 e 2005. 
Tabela 1. Resultados, por UF, de testes sorológicos e virológicos em amostras obtidas pelo Programa Oficial de Vigilância ao Vírus de IA, no sistema de produção comercial avícola intensivo brasileiro, conduzido pelo Mapa, entre 2004 e 2005

\begin{tabular}{|c|c|c|c|c|c|c|}
\hline UF & $\begin{array}{c}\text { Lotes de } \\
\text { amostras a }\end{array}$ & Soros & $\begin{array}{l}\text { Lotes (+) } \\
\text { ELISA }^{\mathbf{b}}\end{array}$ & $\begin{array}{l}\text { Soros (+) } \\
\text { ELISA }^{\mathbf{b}}\end{array}$ & $\begin{array}{l}\text { Soro (+) } \\
\text { IDGA }^{c}\end{array}$ & $\begin{array}{c}\text { Isolamento } \\
\text { viral } \\
\text { negativo }\end{array}$ \\
\hline Bahia & 723 & 10.845 & 192 & 466 & 0 & 678 \\
\hline Distrito Federal & 192 & 2.880 & 47 & 94 & 0 & 91 \\
\hline Espírito Santo & 275 & 4.125 & 86 & 200 & 0 & 153 \\
\hline Goiás & 406 & 6.096 & 121 & 321 & 0 & 189 \\
\hline Mato Grosso & 359 & 5.390 & 81 & 201 & 0 & 202 \\
\hline $\begin{array}{l}\text { Mato Grosso do } \\
\text { Sul }\end{array}$ & 810 & 12.159 & 179 & 356 & 0 & 376 \\
\hline Minas Gerais & 677 & 10.170 & 157 & 416 & 0 & 376 \\
\hline Paraná & 787 & 11.845 & 250 & 832 & 0 & 324 \\
\hline $\begin{array}{l}\text { Rio Grande do } \\
\text { Sul }\end{array}$ & 607 & 9.106 & 194 & 457 & 0 & 194 \\
\hline Rondônia & 57 & 855 & $44^{\mathrm{e}}$ & $206^{e}$ & 0 & $2^{\mathrm{e}}$ \\
\hline Santa Catarina & 752 & 11.341 & 210 & 490 & 0 & 309 \\
\hline São Paulo & 1.219 & 19.005 & 329 & 1102 & 0 & 684 \\
\hline Sergipe & 127 & 1.919 & 46 & 88 & 0 & 102 \\
\hline Tocantins & 26 & 390 & 1 & 1 & 0 & 16 \\
\hline
\end{tabular}

${ }^{\mathrm{a} C a d a}$ lote de amostras foi composto de 15 soros e um lote de 15 suabes de cloaca e 15 suabes de traqueia. Cada suabe continha amostras de duas aves distintas e era armazenado em pool. ${ }^{\mathbf{b}}$ Teste de ELISA. Kit IDEXX FlockChek Avian Influenza Antibody Test Kit. ${ }^{\mathrm{c}}$ Teste de IDGA reagentes cedidos NVSL/APHIS/USDA (Avian Influenza Immunodiffusion Antigen and Antiserum). ${ }^{\mathbf{d}}$ Teste de isolamento viral considerado negativo, após três passagens em ovos embrionados livres de patógenos SPF. ${ }^{\mathbf{e}}$ Amostras submetidas aos testes sorológicos e de isolamento viral, provenientes de Rondônia, não foram suficientes para demonstrar ausência de circulação viral no estado $(p=0,65)$.

Tabela 2. Lista de municípios brasileiros onde a ausência de circulação viral de IA não foi demonstrada por resultados sorológicos. Amostras obtidas pelo Programa Oficial de Vigilância ao Vírus de IA, no sistema de produção comercial avícola intensivo brasileiro, conduzido pelo Mapa, entre 2004 e $2005^{\mathbf{a}, \mathbf{b}}$

\begin{tabular}{|c|c|}
\hline UF & Município \\
\hline Mato Grosso & Alta Floresta \\
\hline Paraná & $\begin{array}{l}\text { Jataizinho, Quatro Pontes, São Manoel do Paraná, São Jorge do Ivaí, União da } \\
\text { Vitória e Vitorino }\end{array}$ \\
\hline Rondônia & $\begin{array}{l}\text { Buritis, Itapoá do Oeste, Ji-Paraná, Monte Negro, Nova Brasilândia do Oeste, } \\
\text { Nova Mamoré } \\
\text { Ouro Preto do Oeste, Presidente Médici, Primavera de Rondônia, Santa Luzia do } \\
\text { Oeste e São Felipe do Oeste }\end{array}$ \\
\hline Santa Catarina & Bom Jesus, Biguaçu, Pinheiro Preto e Ponte Alta \\
\hline Sergipe & Pirambu \\
\hline São Paulo & Álvares Florence, Buri e Tarabaí \\
\hline
\end{tabular}

${ }^{a}$ Amostras submetidas aos testes sorológicos não foram suficientes para demonstrar resultado negativo após realização de teste sorológico $(\mathrm{P}>0,05)$. Prevalência de resultados positivos esperada de $20 \%$. ${ }^{\mathbf{b}}$ Todas as amostras foram submetidas à prova confirmatória de isolamento viral e apresentaram resultado negativo após três passagens em ovos embrionados $S P F$, antes de serem consideradas negativas.

Durante o segundo período do estudo, o serviço veterinário oficial acompanhou a notificação de sintomatologia nervosa e respiratória, seguida de mortalidade acima de $10 \%$, em 886 lotes de produção comercial intensiva de frangos de corte, de 89 municípios dos estados da Bahia, Goiás, Minas Gerais, Mato Grosso, Mato Grosso do Sul, Paraná, Pernambuco, Rio Grande do Sul, Santa Catarina, São Paulo, Sergipe e Tocantins. Foram coletadas 13.275 
amostras de soro. Não houve resultado significativo, que possibilitasse identificar pelo menos um lote suspeito como positivo para IA
$(\mathrm{P}<0,05)$ por prova sorológica. Não ocorreu isolamento de vírus hemaglutinante em qualquer das amostras provenientes deste grupo (Tab. 3).

Tabela 3. Resultados das ações de vigilância para IA no sistema comercial de produção intensiva de aves de corte. Amostras coletadas no período entre 2006 e $2007^{\text {d }}$

\begin{tabular}{lrrrr}
\multicolumn{1}{c}{ UF } & Municípios & Eventos & Amostras $^{\mathbf{a}}$ & $(+)$ ELISA $^{\mathbf{b , c}}$ \\
\hline Bahia & 4 & 8 & 111 & 3 \\
Distrito Federal & 1 & 2 & 30 & 0 \\
Goiás & 2 & 12 & 191 & 0 \\
Mato Grosso & 3 & 32 & 491 & 21 \\
Mato Grosso do Sul & 7 & 82 & 1.241 & 12 \\
Minas Gerais & 2 & 20 & 308 & 30 \\
Paraná & 14 & 89 & 1.337 & 22 \\
Pernambuco & 1 & 9 & 135 & 0 \\
Rio Grande do Sul & 21 & 151 & 2.279 & 122 \\
Santa Catarina & 23 & 388 & 5.820 & 361 \\
São Paulo & 9 & 88 & 1.332 & 40 \\
Sergipe & 1 & 1 & 15 & 0 \\
Tocantins & 1 & 1 & 15 & 0 \\
\hline
\end{tabular}

${ }^{\mathrm{a} C a d a}$ lote de amostras foi composto de 15 soros e um lote de 15 suabes de cloaca e 15 suabes de traqueia. Cada suabe continha amostras de duas aves distintas e era armazenado em pool. ${ }^{\mathbf{b}}$ Resposta positiva ao ELISA. Kit IDEXX® FlockChek Avian Influenza Antibody Test Kit. Resultado não representativo para caracterizar lotes positivos $(\mathrm{p}<0,05)$. ${ }^{\mathrm{c}} \mathrm{Não}$ houve resposta sorológica confirmada em provas de IDGA para IA. Reagentes cedidos NVSL/APHIS/USDA (Avian Influenza Immunodiffusion Antigen and Antiserum). ${ }^{\mathbf{d}}$ Não foi identificada presença de vírus de influenza aviária nas amostras coletadas. Teste de isolamento viral considerado negativo, após três passagens em ovos embrionados livres de patógenos SPF.

Foram investigados 373 lotes de aves reprodutoras, em idade de produção. Os estabelecimentos se localizavam nos estados de Minas Gerais, Mato Grosso, Mato Grosso do Sul, Rio Grande do Sul e São Paulo. Foram testadas 5.593 amostras de soro. Não houve resultado significativo, que possibilitasse identificar pelo menos um lote como positivo para IA $(\mathrm{P}<0,05)$.

A pesquisa de vírus de IA em aves silvestres migratórias ocorreu em 20 sítios de invernada, distribuídos em 12 estados brasileiros, além do Distrito Federal. Foram capturadas 362 aves das espécies Actitis macularia, Arenaria interpres, Calidris fuscicollis, C. pusilla, Calonectris diomedea, Bubulcus ibis, Pluvialis squatarola, Sterna hirundo e Tringa flavipes. Houve isolamento de vírus LPAI, com caracterização sorológica $\mathrm{H} 3$, em quatro amostras, pertencentes às espécies Actitis macularia, Arenaria interpres e Calidris pusilla. Todas pertencem à ordem Charadriiforme. As amostras positivas foram coletadas entre os meses de abril e maio de 2006, em sítios de invernada de aves silvestres localizados nos estados de Pará e Pernambuco (Tab. 4).

Tabela 4. Vírus de IA, isolados em aves silvestres em migração pelo Brasil. Amostras obtidas pelo Programa Oficial de Vigilância ao Vírus de IA, do Mapa, entre 2006 e 2007

\begin{tabular}{llllr}
\multicolumn{1}{c}{ UF } & Município & Coleta & $\begin{array}{c}\text { Ave silvestre } \\
\text { amostrada }\end{array}$ & $\begin{array}{c}\text { Caracterização sorológica } \\
\text { IA }\end{array}$ \\
\hline Pernambuco & Itamaracá & ABR/2006 & Calidris pussilla & H3 \\
\multirow{3}{*}{ Pará } & Salinópolis & MAI/2006 & Actitis macularia & H3 \\
& & & Arenaria interpres & H3 \\
& & & Calidris pusilla & H3 \\
\hline
\end{tabular}


Foram investigadas 3.705 propriedades de aves de criação de subsistência, em 118 municípios, pertencentes a 12 estados do país. Foram investigadas 2.865 aves. Obtiveram-se cinco amostras positivas ao isolamento viral de LPAI, com caracterização sorológica H2, H3 e H4, provenientes das espécies G. gallus e Anas sp., coletadas nos estados de Amazonas, Pará, Pernambuco e Rio Grande do Sul (Tab. 5).

Tabela 5. Vírus de IA, isolados em aves de criação de subsistência. Amostras obtidas pelo Programa Oficial de Vigilância ao Vírus de IA, do Mapa, entre 2006 e 2007

\begin{tabular}{|c|c|c|c|c|}
\hline UF & Município & Coleta & $\begin{array}{l}\text { Espécie } \\
\text { de ave }\end{array}$ & $\begin{array}{l}\text { Caracterização sorológica } \\
\text { IA }\end{array}$ \\
\hline Amazonas & Manaus & SET/2006 & $\begin{array}{l}\text { Gallus gallus } \\
\text { Anas sp. }\end{array}$ & $\begin{array}{l}\mathrm{H} 2 \\
\mathrm{H} 2\end{array}$ \\
\hline Pará & Salinópolis & $\mathrm{ABR} / 2007$ & Gallus gallus & $\mathrm{H} 3$ \\
\hline Pernambuco & Itamaracá & OUT/2006 & Gallus gallus & $\mathrm{H} 3$ \\
\hline Rio Grande do Sul & Tavares & FEV/2007 & Gallus gallus & $\mathrm{H} 4$ \\
\hline
\end{tabular}

${ }^{a}$ Lote de amostras foi composto de suabes individuais de traqueia e suabes das aves de subsistência existentes nas propriedades.

\section{DISCUSSÃO}

Este foi o primeiro estudo de vigilância ativa com o objetivo de verificar a circulação de IA no sistema de produção avícola comercial brasileiro.

Levando-se em conta o fato de IA nunca ter sido previamente notificada no sistema avícola oficial brasileiro, o contato inicial de aves suscetíveis com o vírus de LPAI traduziria na disseminação silenciosa do vírus no sistema de produção avícola comercial, sem aparência de casos clínicos ou mortalidade elevada nos plantéis. Entretanto, em caso de contato com vírus de HPAI, devido à evolução clínica aguda e ao elevado índice de letalidade e mortalidade provocadas, o fato seria percebido rapidamente pelos produtores avícolas e pelo sistema de vigilância oficial (Alexander, 2007). Desta forma, na primeira fase do programa, procedeuse à escolha pela coleta de amostras provenientes de aves sem sintomas clínicos aparentes, de forma a identificar casos precoces de IA, com curso de evolução subclínica.

Poucas referências estão disponíveis sobre os padrões de resultados sorológicos de programas de vigilância para influenza aviária na América do Sul. Os resultados demonstraram ausência de resposta sorológica à circulação de vírus de IA, o que poderia ser explicado pela ausência de contato prévio com o vírus de IA; de outra forma, pela falta de reagentes específicos para as eventuais cepas circulantes no país, ou ainda pelo retardo na produção de resposta sorológica específica das aves.
Além de questões relacionadas à circulação do agente infeccioso no ambiente, as diferenças nos sistemas de biossegurança das granjas, a proximidade aos sítios de aves silvestres e aos criatórios de subsistência, a alta concentração de aves em granjas comerciais e o trânsito intenso de aves têm sido identificados como fatores de risco importantes para a introdução de IA em criatórios comerciais de aves e na produção de marcadores indicativos de novas infecções (Mannelli et al., 2000; Thomas et al., 2005; Minh et al., 2009).

Durante a realização do estudo, a produção avícola comercial de frangos de corte no Brasil estava concentrada na área centro-sul do país. Essa área é caracterizada por manter padronização de condições de manejo, biossegurança e pouca proximidade a sítios de concentração de aves silvestres migratórias. Tais condições contribuem para explicar a ausência de reação sorológica, indicativa de contato prévio com IA, nas amostras provenientes de granjas do sistema comercial intensivo, localizadas nessa área.

Houve apenas a identificação de um conglomerado epidemiológico, formado pela área geográfica de municípios no estado de Rondônia. A análise da k-function indicou um padrão geográfico para os locais, além daqueles em que ocorreu positividade aos testes sorológicos na região, o que poderia significar representar uma área para definição de ações de controle estratégico. $\mathrm{O}$ uso da sede do município como base de representação geográfica da 
origem das amostras impossibilitou detalhamento mais aprofundado (Jacquez e Jacquez, 1999).

O teste de isolamento viral, referência para indicação de infecção, foi realizado em todos os pools de suabes provenientes dos lotes que apresentavam pelo menos uma reação positiva aos testes sorológicos. Não se obteve isolamento de qualquer vírus de IA nas amostras processadas.

As aves migratórias capturadas neste estudo foram provenientes dos continentes americano, africano e europeu (Swayne, 2008). Há necessidade de se identificarem os fatores que não favoreceram estes achados no grupo de aves silvestres capturadas no território brasileiro. Em estudos futuros, haverá uma necessidade de aumentar o universo amostral e de incluir maior diversidade de espécies associadas ao ciclo epidemiológico de circulação de IA nessa população de aves.

Os achados positivos nessa população de aves silvestres migratórias não estão relacionados obrigatoriamente com a possibilidade imediata de introdução e amplificação dos vírus de IA em plantéis avícolas comerciais. Um espaço de tempo entre a infecção de aves silvestres migratórias e a ocorrência de casos na avicultura comercial já foi demonstrado para casos de LPAI, nos Estados Unidos (Halvorson et al., 1985). Como resultado de diversos programas de vigilância para IA, em aves silvestres migratórias, pode-se observar que apenas uma quantidade muito pequena dessas espécies foi encontrada saudável e infectada com cepas H5N1. A maioria encontrava-se doente ou morta (Lvov et al., 2006; Minta et al., 2006).

Os resultados positivos para LPAI, identificados em aves de subsistência, corroboram a afirmação de que essa população representa um risco potencial relevante de exposição à IA. Esses animais, devido ao seu manejo de criação ao ar livre, estão em maior contato com aves silvestres, reservatórios naturais de vírus de IA. Esse risco já foi identificado anteriormente pelo Centers for Disease Control - CDC (Gilbert et al., 2006).

O Departamento de Agricultura dos Estados Unidos definiu um programa de vigilância semelhante em criações avícolas comerciais, baseado na realização de monitoria da população de aves comerciais com sintomatologia clínica. A circulação endêmica de LPAI nos plantéis avícolas comerciais americanos e a liberação de programas de vacinação para IA se traduzem em menores taxas de mortalidade esperadas, nos casos de suspeita de IAAP, fazendo com que o sistema mantenha-se mais constantemente em nível de alerta (USDA, 2006).

Programa de vigilância semelhante em aves silvestres também foi implementado pela DG SANCO, autoridade zoosanitária da União Europeia, para seus países membros (Pittman et al., 2007). Definiram-se atividades de vigilância e prevenção à IA, para detecção precoce de LPAI dos subtipos H5 e $\mathrm{H} 7$ em aves migratórias silvestres e na sua circulação em aves comerciais, com base na realização de amostragem mínima, realizada em cada país membro, conforme sistema produtivo e tamanho da população alojada em cada lote de produção. Neste trabalho, as criações comerciais de anatídeos representam um fator epidemiológico importante na condução das investigações de casos positivos encontrados em populações comerciais de frango de corte. Este poderia se transformar em um relevante ponto de investigação no sistema avícola comercial brasileiro, visto que essa população não foi investigada neste estudo.

As respostas apresentadas nos testes de ELISA para IA serviram de importante fator na investigação epidemiológica em populações susceptíveis nunca expostas ao vírus de IA, uma vez que o teste apresenta especificidade elevada. Entretanto, a ausência de achados de resposta sorológica nas amostras obtidas neste estudo, quando submetidas à IDGA, pode também ser indicativo da necessidade de validação de novos reagentes capazes de capturar anticorpos mais específicos e sensíveis para sorotipos viriais que eventualmente pudessem estar circulando na região.

\section{AGRADECIMENTOS}

Os autores agradecem a todos os funcionários do serviço veterinário oficial brasileiro envolvidos na realização deste trabalho e à União Brasileira de Avicultura - UBA e seus associados, pelo apoio prestado. 


\section{REFERÊNCIAS}

ALEXANDER, D.J. The epidemiology and control of avian influenza and Newcastle disease. J. Comp. Pathol., v.112, p.105-126, 1995.

ALEXANDER, D.J. An overview of the epidemiology of avian influenza. Vaccine, v.25, p.5637-5644, 2007.

BRASIL. Instrução Normativa do Ministério da Agricultura, Pecuária e Abastecimento ${ }^{\circ}{ }^{1}$ 182/1994. Normas de Credenciamento e Monitoramento de Laboratórios para Diagnóstico de Doença de Newcastle, 1994. Disponível em: http://extranet.agricultura.gov.br/sislegis-consulta/ servlet/VisualizarAnexo?id=12700. Acessado em: 23 ago. 2008.

BRASIL. Instrução Normativa do Ministério da Agricultura, Pecuária e Abastecimento $\mathrm{n}^{0}$ 4. Normas para Registro e Fiscalização dos Estabelecimentos Avícolas, $1998 . \quad$ Disponível em: http://extranet.agricultura.gov.br/sislegis/action/detalh aAto.do?method=consultarLegislacaoFederal.

Acessado em: 23 ago. 2008.

BRASIL. IBAMA. Instrução Normativa $n^{0} 27,2002$. Disponível em: http://www2.ibama.gov.br/ cemave/anilha/legisl/in27-2002.htm

CAMERON, A.R.; BALDOCK, F.C. Two stage sampling in surveys to substantiate freedom from disease. Prev. Vet. Med., v.34, p.19-30, 1998.

FAO. Proceedings of the OIE/FAO/IZSVe International Conference on Vaccination, a Tool to Control Avian Influenza. Verona: OIE/FAO, 2007. 195p.

GILBERT M.; CHAITAWEESUB, P.; PARAKAMAWONGSA, T. et al. Free-grazing ducks and highly pathogenic avian influenza, Thailand. Emerg. Infect. Dise., v.12, p.227-34, 2006.

HALVORSON, D.A. A Minnesota cooperative control program. In: EASTERDAY, B.C. (Ed.). Proceedings of the Second International Symposium on Avian lnfluenza. V.S. Anim. Health Association: Richmond, 1987. p.327-336

JACQUEZ, G.M.; JACQUEZ, J.A. Disease Clustering for Uncertain Locations. In: LAWSON, A.; BIGGERI, A.; BOHNING, D. et al. (Eds.). Advanced methods of disease mapping and risk assessment for public health decision making. John Wiley \& Sons Ltd.: West Sussex, 1999. p.151-168.

KULLDORFF, M. SaTScan User Guide for Version 9.0. National Cancer Institute, 2009. Disponível em: http://www.satscan.org. Acessado em: 12 mai. 2011.

KULLDORFF, M.; NAGARWALLA, N. Spatial disease clusters: detection and inference. Statistics in Med.. v.14, p.799-810, 1995.
LVOV, D.K.; SCHELKANOV, M.I.U.; DERIABIN, P.G. et al. Isolation of influenza $\mathrm{A} / \mathrm{H} 5 \mathrm{~N} 1$ virus strains from poultry and wild birds in west Siberia during epizooty (July 2005) and their depositing to the state collection of viruses (August 2005). Vopr. Virusol., v.51, p.11-14, 2006.

LVOV, D.K.; ZDANOV, V.M.; SAZONOV, A.A. et al. Comparison of influenza viruses isolated from man and from whales. Bull. World Health Organizat., v.56, p.923-930, 1978.

MANNELLI A.; FERRE, N.; MARANGON, S. Analysis of the 1999-2000 higly pathogenic avian influenza $(\mathrm{H} 7 \mathrm{~N} 1)$ epidemic in the main poultryproduction area in northern Italy. Prev. Vet. Med., v.73, p.273-285, 2000.

MINH, Q.P.; MORRIS, R.S.; SCHAUER, B. et al. Spatio-temporal epidemiology of highly pathogenic avian influenza outbreaks in the two deltas of Vietnam during 2003 - 2007. Prev. Vet. Med., v.89, p.16-24, 2009.

MINTA, Z.; SMIETANKA, K.; DOMANSKABLICHARZ, K. et al. HPAI H5N1 infection of a mute swan flock in the city of Torun in Poland. In: Joint Twelfth Annual Meetings of the National Laboratories for Newcastle Disease and Avian Influenza of European Union Member States 2006.

OIE, World Organization for Animal Health Terrestrial Animal Health Code, 2007. Disponível em: http://www.oie.int/eng/normes/mcode/A_summry.htm ?e1d11.

OIE. Manual of diagnostic tests and vaccines for terrestrial animals. Paris: OIE, 2004, 628p.

PITTMAN M.; LADDOMADA, A.; FREIGOFAS, R. et al. Surveillance, prevention, and disease management of avian influenza in the european union. J. Wildlife Dis., v.43, p.S64-S70, 2007.

SWAYNE, D.E. Avian Influenza. Oxford: Blackwell Publishing Ltd., 2008. p.605.

THOMAS, M.E.; BOUMA, A.; EKKER, H.M. et al. Risk factors for the introduction of highly pathogenic Avian Influenza virus into poultry farms during the epidemic in the Netherlands in 2003. Prev. Vet. Med., v.69, p.1-11, 2005.

USDA 2006. Summary of the National Highly Pathogenic Avian Influenza (HPAI) Response Plan. Disponível em: http://www.aphis.usda.gov/newsroom/hot_issues/avia n_influenza/contents/printable_version/SummaryHPA I-Response092007Draft.pdf . Acessado em: 16 jun. 2008

WEBSTER, R.G.; BEAN, W.J.; GORMAN, O.T. et al. Evolution and ecology of influenza A viruses. Microbiol. Rev., v.56, p.152-179, 1992. 